\title{
An ex-ante evaluation of last-mile freight distribution services for city logistics
}

\author{
L. Amodeo, D. Lamari, G. Musolino, V. Placido, A. Polimeni, \\ M. Praticò \& A. Vitetta \\ DIIES - Dipartimento di Ingegneria dell'Informazione, delle \\ Infrastrutture e dell'Energia Sostenibile, \\ Università Mediterranea di Reggio Calabria, Italy
}

\begin{abstract}
The paper deals with methodologies to support an ex-ante assessment of the impacts generated by the introduction of city logistics measures on last-mile freight distribution services. Some models and algorithms are applied and compared to solve the vehicle routing problem for freight deliveries in the town of Reggio Calabria with the introduction of an urban distribution centre and of green freight vehicles. Heuristic routing algorithms are compared in terms of sequence of clients (retailers) visited subject to some constraints given by the presence of UDC and the limited autonomy and capacity of freight vehicles.
\end{abstract}

Keywords: city logistics, urban distribution centre, freight vehicle routing, Fuelled-Electric Vehicles.

\section{Introduction}

City logistics aims to reduce negative externalities generated by freight transport without depressing the economic and social vitality of urban areas.

The above goals may be reached by means of a wide range of city logistics measures. They may related to [1,2]: physical infrastructures, subdivided into linear infrastructures (i.e. roads reserved to freight vehicles only) and surface infrastructures (and/or nodal), such as loading/unloading areas, distribution centres; immaterial infrastructures, such as research and education, Intelligent Transport Systems (telematics); equipment, relevant to loading units (new standards) or transport units (e.g. low impact vehicles); governance, such as 
delivery/pick up time windows, road pricing, traffic restrictions to categories of vehicles.

In order to estimate and evaluate the impacts generated by city logistics measures [3], an important role is played by simulation and design models which should be able to reproduce the distribution process inside the urban area.

In the above context, the paper presents some models and algorithms for Vehicle Routing Problem (VRP) in city logistics. Recently, multi-level distribution schemes have been implemented in several cities where freight reach an intermediate facility before being delivered to the final destinations. This facility, generally called Urban Distribution Centre (UDC), can be a warehouse, a transhipment site or a cross-docking facility [4].

There are two main reasons that push for the realization of the UDCs. Firstly, they potentially allow the increase in degree of consolidation of freight flows, reducing traffic congestion, pollution and cost [5]. Secondly, many cities limit (or are planning to limit) the vehicle circulation in central areas, allowing only fully-loaded green vehicles, such as Fuelled-Electric Vehicles (FEV). Because of their limited autonomy and loading capacity, UDCs are needed to support their usage. In this context, there is the tendency to develop the service with electrical and/or Euro VI vehicles in accordance with the goal indicated by the EU [6].

The purpose of the paper is to apply consolidated VRP models to support an ex-ante evaluation of the effects of new schemes that arise from the realization of a UDC on the freight distribution process.

The paper is structured into four sections. Section 2 presents the characteristics of a UDC and the experiences connected to their implementation in some urban contexts and a brief state-of-the-art VRP for city logistics. Section 3 reports the main elements of the proposed design models and algorithms to solve the VRP for city logistics. Section 4 reports the results of the application and comparison of some existing algorithms to define routes of fully-loaded fuelled-electric freight vehicles that have to deliver not-perishable goods from the UDC to clients (retailers). Some conclusions are presented in the last section.

\section{Existing literature on urban distribution centres and routing}

This section presents a brief literature review on the main two elements that characterize the multi-level freight distribution schemes in urban areas: UDC and VRP.

A UDC may be defined as "a facility involving the transhipment of goods directed to urban areas, aiming to consolidate deliveries, and thus provide greater efficiency" (and effectiveness) "in the distribution process by increasing the truck load factor and decreasing the number of trucks used, which help mitigate urban congestion and air pollution" (see [7]).

The UDC shapes a multi-level scheme in the urban freight distribution process, which allows freight to be carried by means of larger vehicles outside the city and, after the transhipment, by means of smaller and less polluting vehicles inside the city. 
The transhipment operation increases the costs connected to handling, ordering, inventory, damage and loss; but it could give benefits connected to the consolidation of the consignments and the optimization of freight vehicle routes and loads.

The entity of costs and benefits connected to the UDC depends on several elements connected to [7-9]: structure and regulations of urban transport facilities and services; physical, organizational and governance elements of the UDC; characteristics of carriers and end-users (e.g. retailers); type of freight to be delivered.

Although UDCs have been planned and implemented in several European cities, some of them closed after some years from their implementation.

Some general lessons learned from existing studies on UDCs are reported in the following (see [9]). Bottom-up initiatives seem more successful than topdown ones because shippers, carriers and retailers have been involved in UDCs' implementation since an early stage, providing their decisive contribution in the achievement and maintenance of the break-even threshold [10]. Traffic restrictions to freight transport operations, such as time windows, vehicle weight or speed limits, green vehicles, tend to facilitate the implementation of UDCs, if operators accept the restrictions or if they are fully or partly subject to the restrictions. UDCs seems to work potentially better for deliveries with a high frequency, low volume, and which contain simple products. According to [11], the major potential beneficiaries of a UDC are independent and small retailers, since their logistics is generally not optimized (in contrast to those of retail chains), as well as carriers making small multi-drop deliveries in restricted areas to the circulation of freight vehicles.

The VRP, introduced in 1959 by Dantzig and Ramser [12], has evolved in recent years to take into account the new needs introduced in the freight distribution (as an example, one of the goals in the European White Paper [13] is the reduction by the year 2030 of greenhouse gas emissions by $20 \%$ compared to 2008). Among measures to regulate the freight transport in an urban area, it is possible to optimize vehicle routes to minimize, as an example, the pollutant emission or the energy consumption (this last element is crucial when using FEVs in the distribution). In this field, several works are presented in literature. Without being exhaustive, some of those are reported in the following. Referring to the emission minimization, [14] proposes an ecologically oriented vehicle routing with the objective of minimizing the $\mathrm{CO}_{2}$ emission in relation to the distance travelled and the fuel consumed. Figliozzi [15] proposes a formulation assuming the speed as dependent on time. Considering a set of time intervals, mono and multi objective problems are formulated with the aim of minimizing the vehicle number, the emissions, the distance travelled and the route cost. In the first case, a formulation at three levels has been proposed; in the second case, a total cost formulation is provided. Scott et al. [16] investigate the influence on emissions in freight distribution due to the road topology and the vehicle payload. The objective functions indicated refer to distance and emission level considering various scenarios. A work focused on the investigation of these 
routing problems is proposed in [17], while an exhaustive survey on VRP models and algorithms is reported in [18].

Referring to the energy minimization, if the used vehicle is electric, it is fundamental to design the best paths [19]. A model to estimate the electric vehicles' energy consumption is proposed in [20] analysing the link among vehicle power, speed, acceleration and the road slope. Similarly, [21] examines some variants of the fuel consumption in the vehicle routing problem. In [22] a problem formulation that considers the fuel consumption as proportional to the distance travelled, and independent of the vehicle load and speed, is proposed. This formulation provides the option to add in the tour one (or more) refuelling stations to allow the vehicles the opportunity to continue the tour. Similarly, in [23] the energy consumption is considered as the product between the curb weight and the distance travelled.

The use of a consolidation centre as a means to reduce the freight distribution, in terms of attraction model and impacts, is investigated in some papers [24-27]. Particularly, in [27] the case is examined in which the last mile is covered by electric vehicles.

\section{Model and procedures for design freight deliveries to clients}

The type of trips' object of analysis are the restocking (acquisition) trips, which allow delivering freight from the UDC to retailers. These trips are performed by means of so-called push movements, where a specific firm (private or public) operates the freight delivery to the retailer, who can give some indications regarding the delivery time. This method is implemented is some European cities, as reported in [28]. In the next two sections the problem formulation (section 3.1) and some solution procedures (section 3.2) are provided.

\subsection{Problem formulation}

An Energy Minimizing Vehicle Routing Problem (EMVRP) is formulated with the aim of minimizing energy consumption by FEVs. The basic assumptions are:

1) energy consumption depends on distance travelled, but it is independent of the vehicle load;

2) path costs are evaluated in terms of energy consumption.

According to the above assumptions, the cost $g_{k(r, s)}$ of a path $k_{(r, s)}$ between origin $\mathrm{r}$ and destination $\mathrm{s}$ (where $\mathrm{r}$ and $\mathrm{s}$ are the UDC and the clients to be served) is:

$$
g_{k(r, s)}=\Sigma_{j} \delta_{k j} \cdot \varpi\left(l_{j}\right)
$$

where:

$\delta_{k j}$ is equal to 1 if the link $j$ belongs to the path $k$; 0 otherwise;

$\varpi($.$) is a function to evaluate the energy consumption on link j$, depending on the link length $l_{j}$.

The formulation of the EMVRP can be expressed as:

$$
\Phi(\boldsymbol{X})=\Sigma_{v}\left(\Sigma_{r} \Sigma_{s}\left(g_{k(r, s)}\right) \cdot x_{k(r s) v}\right)
$$


where:

$v$ is a generic vehicle;

$(r, s)$ is the origin destination pair;

$x_{k(r s) v}$ is the design binary variable (is equal to 1 if the vehicle $v$ use the path $k_{(r, s)}$ 0 otherwise).

The EMVRP is a constrained problem: (1) only one vehicle can visit a node; (2) all vehicles leave from the depot and come back to it; (3) the load cannot exceed the capacity; (4) the duration (or the length) of a route cannot exceed a maximum value; (5) the energy consumed is less than the battery capacity; (6) the variable $x_{k(r s) v}$ can assume the values zero or one.

Constraints (1-4) are classical constraints of the VRP; constraint (5) can be relaxed if charging stations are present in the study area. Constraint (6) indicates that the variable is binary.

\subsection{Solution procedures}

The VRP is often solved by means of sophisticated algorithms, as seen in literature review section, but in some cases rough heuristics can be used to quickly solve the problem. In this section, a greedy algorithm, an (homogenous) area algorithm and the general steps of a genetic algorithm are reported. In Section 4, an application is performed using the three algorithms and the results are compared.

The greedy algorithm is a heuristic able to solve the problem in a simple and immediate way. The heuristic searches a solution of the EMVRP with sequential insertions (with local optimum search) of users in the route taking into account the problem constraints. The essential steps of a greedy algorithm are reported in Figure 1. The step 0 is the initialization of the procedure: from the set of the clients, the client closer to the depot is chosen and inserted in the route as the first client to reach in relation to the value of the objective function (eq. (2)). In step 1, the route is updated by inserting the closest client, in relation to the value of the objective function and the constraints' thresholds. In step 2, the procedure ends if all clients are visited.

The area algorithm makes a partition among the clients to be visited. They are partitioned into homogenous areas according to the transport network and landuse criteria. The clients are inserted in relation to the distance and the vehicle load in each area. The total freight to deliver is equal, or less, to the capacity of each vehicle. The number of runs of the greedy algorithm is equal to the number of partitioned areas.

The genetic algorithm is a well-known bio inspired algorithm able to solve the EMVRP employing operators. The essential steps of a genetic algorithm are reported in Figure 2. Starting from an initial and feasible set of solutions (step 0, note that the greedy algorithm can be used to generate it), a selection procedure (step 1) is called to create a set, the mating pool, of solutions that are subjected to the operations of crossover and mutation (steps 2 and 3). The crossover consists of the crossing of two solutions (parents) to generate two children that replace the parents in the next iteration. The mutation consists of switching the position of one or more clients to be visited inside a route. The variability of this 
operation allows us to explore a solution space larger than the one considered in the greedy algorithm. The procedure ends when a maximum number of iterations is reached (step 4).

\section{Step 0: Route initialization}

The set of clients contains all the clients not visited by a definitive route.

The current route contains the depot and the client belonging to the set of clients and closest to the depot; delete the selected client from the set of clients.

\section{Step 1: Route generation}

Update the current route by inserting the closest client (in relation to the value of the objective function) to the previous one and delete it from the set of clients, until the constraints thresholds (e.g. capacity, energy consumption including coming back trip to the depot) are not exceed.

The current route, including also coming back trip to the depot, is definitive.

\section{Step 2: End of the procedure}

If the set of client is empty end the procedure; else go to the step 0.

Figure 1: Greedy algorithm.

\section{Step 0: Initialization}

Create the initial feasible population.

\section{Step 1: Selection}

From the initial population, select the elements (solutions) to insert in the mating pool in relation to the value of the objective function.

\section{Step 2: Crossover}

From the mating pool, choice (randomly) the parents (solutions) and cross it. A couple of parents generate two children that replace it in the new generation.

\section{Step 3: Mutation}

From the population, choice a set of solution and switch randomly the position of one or more users in the route.

\section{Step 4: End procedure}

The algorithm end when an established number of iteration is performed.

Figure 2: Genetic algorithm.

\section{Application}

The algorithms are tested and compared for the town of Reggio Calabria, where a new UDC has been planned.

The application started with the definition of the study area, which consists of the central district with mixed residential and retail activities and clustered educational and public services. A number of 23 node-clients and a UDC are identified inside the study area. The total quantity of freight to be delivered is $8 \mathrm{~m}^{3}$. The long-haul road transport service to supplying the UDC is studied in [29]. 
The city logistic plan foresees the use of fully-loaded FEVs. In particular, two vehicle configurations are tested: the first one considers two FEVs, with a capacity of $4.1 \mathrm{~m}^{3}$ each, and the second considers three FEVs, with a capacity of $3.0 \mathrm{~m}^{3}$ each. The autonomy constraint is not active in the application considering the generated routes. The three algorithms described in the previous section are applied.

The results are presented in the following. Table 1 shows the route times of a single vehicle calculated for each routing algorithm and for each vehicle configuration. The greedy algorithm with two vehicles estimates 30 minutes with the first vehicle and 54 minutes with the second vehicle, for a total time (without considering the load/unload time at node-client) of 84 minutes. The estimates with three vehicle estimates are 26 minutes, 40 minutes and 34 minutes for each vehicle for a total time of 100 minutes. The area algorithm with two and three vehicles estimates route times than are intermediate than the greedy one: the total time for two vehicles is 89 minutes and the total time for three vehicles is 87 minutes. The genetic algorithm estimates lower route times in both cases of two and three vehicles: the total time for two vehicles is 66 minutes and the total time for three vehicles is 73 minutes.

Table 2 and Figures 3 and 4 show the sequences of nodes visited calculated in the six cases generated from the combination of the three algorithms and the two vehicle configurations.

According to the results obtained, the following considerations may be drawn:

- the genetic algorithm provides lower route times than the ones provided by the greedy and area algorithms: there is a trade-off between the higher quality of the results obtained with the former and the simplicity and immediate applicability of the latter;

- the percentage of reduction of the route times obtained with genetic algorithm is about 10-20\%, which is a relevant reduction both in terms of energy consumption (and monetary costs) from the carrier standpoint and in terms of pollution from the community standpoint;

- routes designed by the genetic algorithm are composed by groups of clustered nodes-clients close to one another, linked together by means of more extended paths; this configuration cannot be designed by the greedy algorithm, nor by the area one (where the space is exogenously partitioned);

- the relevant reduction of the genetic algorithm is obtained in a simple case, with only 23 clients and two/three vehicles; greater reductions are expected with increasing number of clients to be visited and more vehicles used;

- greedy and area algorithms emulate the decisions of small retailers and carriers whose logistics is not optimized and not present in the town respectively, while the genetic algorithm obtains a solution similar to the one that could be obtained with the support of a decision support system. 
Table 1: $\quad$ Route times without considering the load/unload time (minutes).

\begin{tabular}{ccc}
\hline & \multicolumn{2}{c}{ Number of vehicles } \\
\cline { 2 - 3 } Algorithm & 2 & 3 \\
\hline Greedy & 84 & 100 \\
\cline { 2 - 3 } Area & 89 & 87 \\
\hline Genetic & 66 & 73 \\
\hline
\end{tabular}

Table 2: $\quad$ Sequences of nodes-clients to be visited.

\begin{tabular}{ccc}
\hline \multirow{3}{*}{ Algorithm } & \multicolumn{2}{c}{ Number of vehicles } \\
\cline { 2 - 3 } Greedy & UDC-23-4-2-5-6-8-9-10-3-UDC & 3 \\
& UDC -7-11-13-22-18-15-20-21-19-14- & UDC -9-10-3-7-11-13-22-18-15-20-21- UDC \\
& $12-16-17-1-$ UDC & UDC -19-14-12-16-17-1- UDC \\
\cline { 2 - 3 } Area & UDC -4-2-23-6-5-8-3-1- UDC & UDC -4-2-23-6-5-1- UDC \\
& UDC-16-22-18-15-20-21-19-14-12-9- & UDC -3-8-9-10-11-7-13- UDC \\
& $10-13-11-7-17-$ UDC & UDC -16-12-22-18-15-20-21-19-14-17- UDC \\
\hline \multirow{3}{*}{ Genetic } & UDC-1-16-12-22-18-15-20-21-19-17- & UDC-4-16-12-22-18-15-20-21-19-17-14-2- \\
& UDC-4-2-23-3-8-13-10-9-11-7-6-UDC & UDC-8-13-10-9-11-7-3-UDC \\
& & UDC-1-23-6-5-UDC \\
\hline
\end{tabular}

\section{Conclusion}

The paper presents heuristic algorithms to solve the VRP for freight deliveries in an urban area in the case of introduction of an UDC and of green freight vehicles.

The algorithms are applied and compared in terms of route travel times and of sequence of clients (retailers) visited subject to constraints given by the UDC and the limited autonomy and capacity of freight vehicles.

The comparison of the routing algorithms shows that the reduction of times obtained with a genetic algorithm is about $10-20 \%$. Therefore, the simplicity and applicability of the greedy and area algorithms are paid by the lower quality of the results.

Consolidated VRP algorithms could provide a useful support to local authorities and carriers as operational tools in ex-ante evaluating the new distribution schemes generated by the introduction of an UDC and of green freight vehicles.

Future work will pursue two directions. The application of a system of urban freight demand models in order to obtain an aggregate estimation of freight demand levels. The development of a technical and financial feasibility study of the planned UDC in the town of Reggio Calabria. 


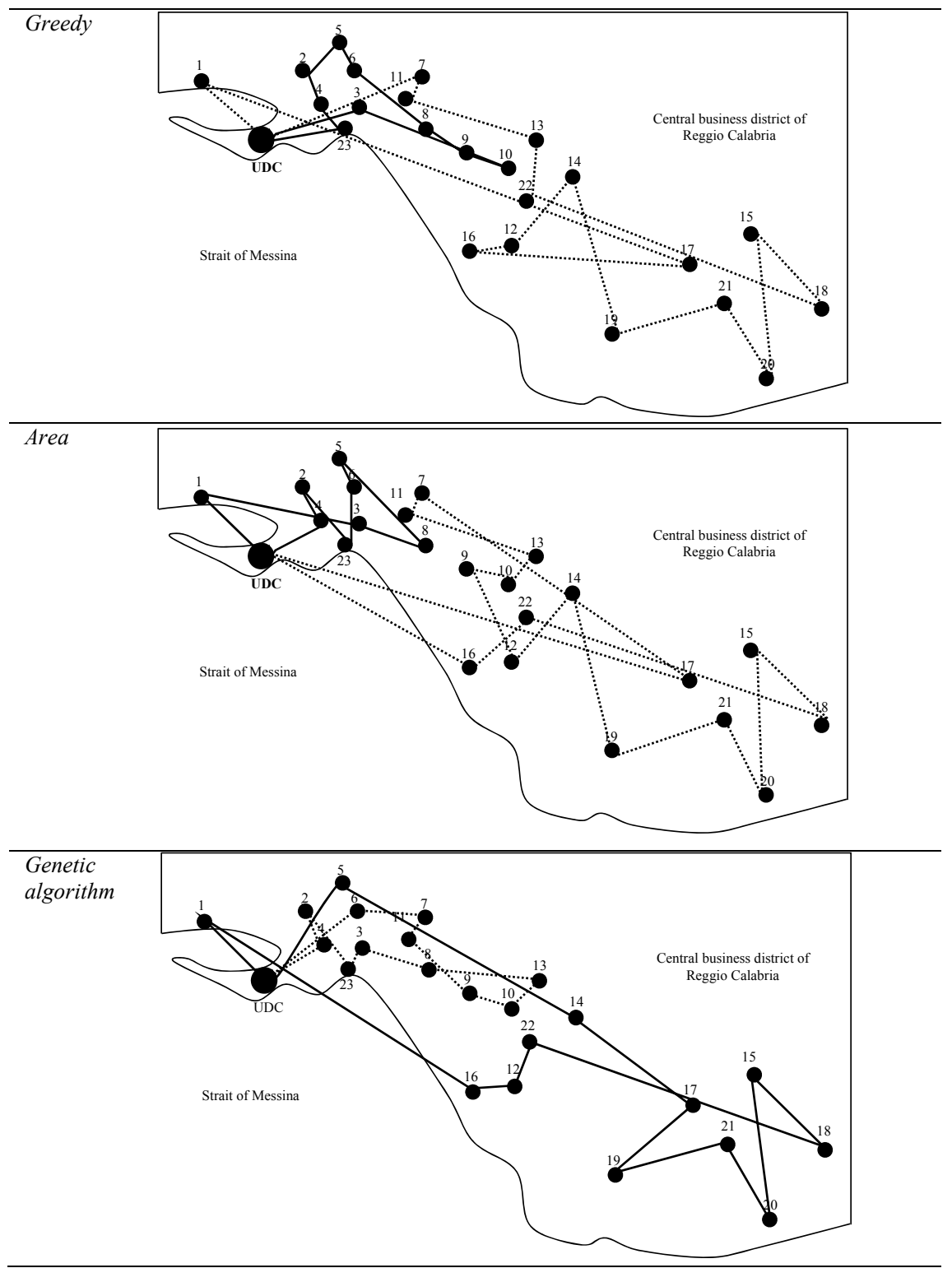

Figure 3: Best routes with two vehicles: greedy, area and genetic algorithms. 


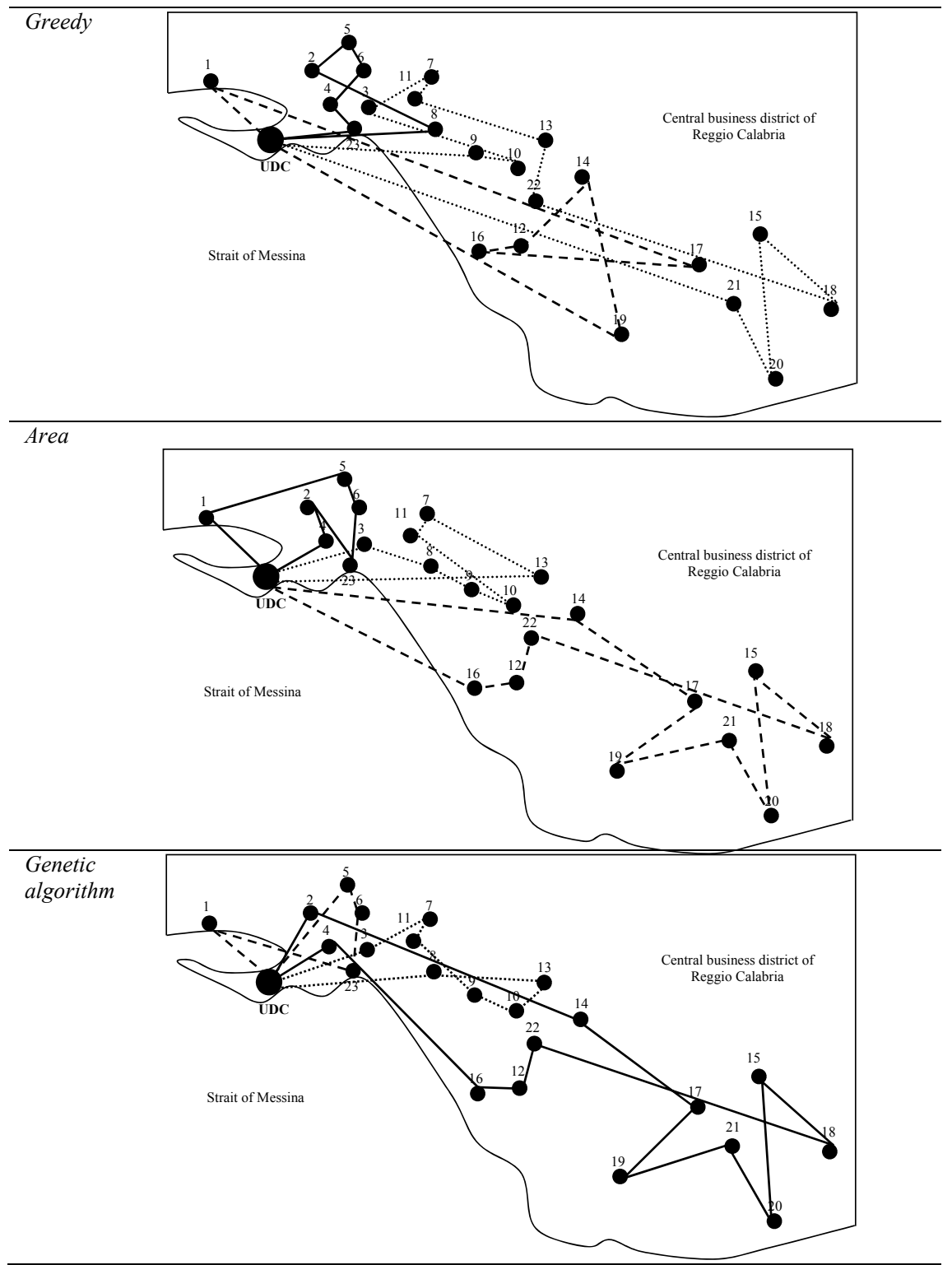

Figure 4: Best routes with three vehicles: greedy, area and genetic algorithms. 


\section{Acknowledgements}

Luciano Amodeo, Domenicantonio Lamari, Vincenzo Placido and Massimo Praticò collaborated with the application as students of the Master of Transportation Engineering, supplied in 2014-2015 at Dipartimento di Ingegneria dell'Informazione, delle Infrastrutture e dell'Energia Sostenibile of Università Mediterranea di Reggio Calabria.

\section{References}

[1] Russo F., Modeling behavioral aspects of urban freight movements. In: Freight Transport Modeling, M. Ben-Akiva, H. Meersman \& E. Van de Voorde (eds), Emerald Group Publishing Limited, 2013. ISBN 978-17819-285-1.

[2] Russo, F. \& Comi, A., A classification of city logistics measures and connected impacts. Procedia - Social and Behavioral Sciences, 2 (3), pp. 6355-6365, 2010.

[3] Russo, F. \& Comi, A., A model system for the ex-ante assessment of city logistics measures. Research in Transportation Economics, 31 (1), pp. 8187, 2011.

[4] Cattaruzza D., Absi N., Feillet D., González-Feliu J., Vehicle Routing Problems for City Logistics, EURO Journal on Transportation and Logistics, 2015, DOI 10.1007/s13676-014-0074-0.

[5] COST 321, Urban goods transport - final report of the action. Belgium: Transport Research, European Commission Directorate General Transport, 1998.

[6] European Commission (2011), White Paper. Roadmap to a Single European Transport Area - Towards a competitive and resource efficient transport system. Available at: http://eur-lex.europa.eu/legal-content/ EN/TXT/PDF/?uri=CELEX:52011DC0144\&from=EN (accessed March 2015).

[7] Tario J. D. et al., Urban distribution centers: a means to reducing freight vehicle miles travelled. Final Report. Prepared for the New York State Energy Research and Development Authority. Albany, NY, 2011.

[8] Danielis R. \& Marcucci, E., The potential demand for a urban freight consolidation centre. Transportation, 35. pp. 269-284, 2008.

[9] Russo, F., Musolino, G.,Trecozzi, M.R., A system of models for the assessment of an urban distribution center in a city logistic plan, WIT Transactions on the Built Environment, Vol. 130, pp. 799-810, 2013.

[10] Quak, H., Sustainability of urban freight transport. Retail distribution and local regulations in cities. Erasmus University, Rotterdam, 2008.

[11] Browne, M., Sweet, M., Woodburn, A. \& Allen, J., Urban Freight Consolidation Centres. Final Report. Department of Transport, UK, 2005.

[12] Dantzig, G. B. \& Ramser, J. H., The truck dispatching problem. Management Science, 6 (1), pp. 80-91, 1959.

[13] http://ec.europa.eu/transport/themes/strategies/2011_white_paper_en.htm

[14] Kopfer H. W. \& Kopfer H., Emissions Minimization Vehicle Routing Problem in dependance of different vehicle classes. In: J. Kreowski et al. 
(eds.), Dynamics in Logistics, Lecture Notes in Logistics, Springer-Verlag Berlin Heidelberg, 2013.

[15] Figliozzi M., Vehicle routing problem for emissions minimization. transportation research record: journal of the transportation research board, 2197, 1-7, 2010.

[16] Scott C., Urquhart N. \& Hart E., Influence of Topology and Payload on CO2 Optimised Vehicle Routing. In: C. Di Chio et al. (Eds.): EvoApplications 2010, Part II, LNCS 6025, 141-150, 2010.

[17] Lin, C., Choy, K.L., Ho, G.T.S., Chung, S.H. \& Lam, H.Y., Survey of green vehicle routing problem: past and future trends. Expert Systems with Applications, 41(4), pp. 1118-1138, 2014.

[18] Canhong Lin, Choy K.L., Ho G.T.S., Chung S.H., Lam H.Y., Survey of Green Vehicle Routing Problem: Past and future trends, Expert Systems with Applications, Volume 41, Issue 4, Part 1, pp. 1118-1138, 2014.

[19] Schönfelder R., Leucker M.\& Walther S., Efficient Profile Routing for Electric Vehicles Internet of Vehicles - Technologies and Services, Lecture Notes in Computer Science, 8662, pp. 21-30, 2014.

[20] Wua X., Freese D., Cabrera A. \& Kitch W. A., Electric vehicles' energy consumption measurement and estimation. Transportation Research Part $D, 34,52-67,2015$.

[21] Gaur D. R., Mudgal A. \& Singh R. R., Routing vehicles to minimize fuel consumption. Operations Research Letters, 41, 576-580, 2013.

[22] Erdogan S. \& Miller-Hooks E., A Green Vehicle Routing Problem. Transportation Research Part E, 48,100-114, 2012.

[23] Kara I., Kara B. Y. \&Yetis M. K., Energy Minimizing Vehicle Routing Problem. In: A. Dress, Y. Xu, and B. Zhu (Eds.): COCOA 2007, LNCS 4616, pp. 62-71, 2007.

[24] Russo, F. \& Comi, A., Urban freight movement: A quantity attraction model. Advances in Transport, pp. 831-840, 2002.

[25] Moutaoukil A., Neubert G. \& Derrouiche R., A Comparison of Homogeneous and Heterogeneous Vehicle Fleet Size in Green Vehicle Routing Problem. In: B. Grabot et al. (Eds.): APMS 2014, Part II, IFIP AICT 439, pp. 450-457, 2014.

[26] Ubeda S., Arcelus F.J. \& Faulin J., Green logistics at Eroski: a case study. Int. J. Production Economics, 131, pp. 44-51, 2014.

[27] Browne M., Allen J. \& Leonardi J., Evaluating the use of an urban consolidation centre and electric vehicles in central London. IATSS Research, 35(1), 1-6, 2011.

[28] Creazza A., Curi S. \& Dallari F., City logistics: panoramica delle best practice nazionali e internazionali, LIUC papers n. 271, Serie Tecnologia 26, febbraio 2014.

[29] Russo F., Rindone C., D’Agostino P., Lanciano C. \& Scattarreggia T., Long distance freight transport to the provisioning of a city logistics. In WIT Transactions on the Built Environment, volume 146, 2015. ISSN: 1746-4498, Digital ISSN: 1743-3509. 